\title{
Anchorage-independent growth of Ewing sarcoma cells under serum-free conditions is not associated with stem-cell like phenotype and function
}

\author{
KATHARINA LEUCHTE ${ }^{1}$, BIANCA ALTVATER ${ }^{1}$, SIMEON HOFFSCHLAG ${ }^{1}$, JENNY POTRATZ $^{1}$, JUTTA MELTZER ${ }^{1}$, \\ DAGMAR CLEMENS ${ }^{1}$, ANDREA LUECKE ${ }^{1}$, JENDRIK HARDES ${ }^{2}$, UTA DIRKSEN ${ }^{1}$, HERIBERT JUERGENS ${ }^{1}$, \\ SAREETHA KAILAYANGIRI $^{1 *}$ and CLAUDIA ROSSIG ${ }^{1 *}$
}

${ }^{1}$ Department of Pediatric Hematology and Oncology, University Children's Hospital Muenster;

${ }^{2}$ Department of Orthopedic Surgery, University Hospital Muenster, D-48149 Muenster, Germany

Received April 9, 2014; Accepted May 8, 2014

DOI: 10.3892/or.2014.3269

\begin{abstract}
Novel treatment strategies for Ewing sarcoma aim to eliminate residual tumor cells that have maintained the capacity to reinitiate tumor growth after intensive conventional therapy. Preclinical models that more closely mimic in vivo tumor growth than standard monolayer cultures are needed. Sphere formation under anchorage-independent, serum-free conditions has been proposed to enrich for cells with tumorinitiating, stem cell-like properties in various solid cancers. In the present study, we assessed the phenotype and functional stem cell characteristics of Ewing sarcoma spheres. Spheres were generated under serum-free culture conditions from four Ewing sarcoma cell lines and four relapse tumor biopsies. Standard monolayer cultures were established as controls. Median levels of surface expression of the Ewing sarcoma marker CD99 as well as the supposed stem cell marker CD133 and the neural crest marker CD57 were comparable between spheres and monolayers. Ewing sarcoma spheres from individual tumors failed to continuously self-renew by secondary sphere formation. They contained variable proportions of side populations (SPs). Sphere culture did not enhance the in vivo tumorigenicity of Ewing sarcoma cells in a murine xenograft model. We conclude that sphere formation under serumfree conditions is not a reliable tool to enrich for cells with stem cell characteristics in Ewing sarcoma. By mimicking the anchorage-independent, multicellular growth of Ewing sarcoma micrometastases, in vitro sphere growth may still
\end{abstract}

Correspondence to: Professor Claudia Rossig, Department of Pediatric Hematology and Oncology, University Children's Hospital Muenster, Albert-Schweitzer-Campus 1, D-48149 Muenster, Germany E-mail: rossig@uni-muenster.de

*Joint senior authorship

Key words: Ewing sarcoma, anchorage-independent cell growth, spheres, self-renewal, tumorigenicity add value as a preclinical tool to evaluate the efficacy of novel therapeutics.

\section{Introduction}

Ewing sarcoma is an aggressive primary bone cancer with a characteristic age peak in adolescents and young adults. State of the art treatment consists of multiagent chemotherapy and regional tumor control by surgery and/or radiotherapy and cures $>70 \%$ of patients with localized disease and even with primary pulmonary metastases (1). However, the disease remains fatal in most patients with tumor dissemination to bone and/or bone marrow (2). The patients often show marked, even complete response to chemotherapy, but systemic relapse almost inevitably follows (3). This pattern of relapse is suggestive of a model of tumor growth in which rare residual cells that have survived the intensive chemotherapy have maintained the capacity to reinitiate the tumor. Tumorigenic potential of individual cells is a key consideration for the design of novel immunological (4-6) and molecularly targeted (7) therapeutic strategies, which must target all cells contributing to the disease to be effective. Over standard monolayer cultures, in vitro tumor models that reflect the three-dimensional structure of (micro)metastatic tumor growth $(8,9)$ and the capacity of tumor cell subsets to reinitiate the disease may be more adequate to predict the clinical activity of novel targeting strategies. In many malignancies, sphere formation has been proposed to enrich for cells with stem cell-like properties $(10,11)$, particularly when cells were cultured under serum-free conditions aiming to prevent cellular differentiation (12). Indeed, tumor spheres in Ewing sarcoma have been found to recapitulate the histopathology of primary tumors and to activate signaling pathways associated with in vivo tumor growth and survival (13). One study further indicated a higher tumor-initiation capacity of sphere-cultured Ewing sarcoma cells (14). These studies have been limited to established tumor cell lines or cultures that have undergone several previous passages as monolayers. Here, we investigated the phenotypes and functional stem cell characteristics of Ewing sarcoma spheres generated under 
serum-free culture conditions from established cell lines as well as from low-passage cell cultures newly established from tumor biopsies.

\section{Materials and methods}

Cell lines. The Ewing sarcoma cell lines VH-64 after multiple and after only 3 in vitro passages following isolation from a malignant pleural effusion (VH-64-EP), and WE-68 cells were gifts from Frans van Valen's laboratory at the Institute of Experimental Orthopedics of University of Muenster, Germany. TC-71 was purchased from DSMZ (Braunschweig, Germany). Both cell lines were characterized by the EuroBoNeT consortium (15). A-4573 and TC-32 were from the cell line bank at Children's Hospital Los Angeles. The identity of the cell lines was confirmed by short tandem repeat (STR) profiling. For standard adherent growth, tumor cells were cultured in collagen-coated $25 \mathrm{~cm}^{2}$ tissue culture flasks (VH-64) or in uncoated flasks (all others) in RPMI-1640 medium (Invitrogen, Darmstadt, Germany), supplemented with $10 \%$ heat-inactivated fetal calf serum (FCS; Thermo Fisher, Bonn, Germany) and $2 \mathrm{mM} \mathrm{L-glutamine}$ and maintained at $37^{\circ} \mathrm{C}$ and $5 \% \mathrm{CO}_{2}$. To generate primary Ewing sarcoma cell cultures, biopsy material from metastatic relapse tumors in four pediatric and young adult patients was dissected into 1-2 $\mathrm{mm}$ fragments, incubated in trypsin $(0.05 \%)$ /EDTA $(0.02 \%)$ solution (PAA, Cölbe, Germany), and passed through a cell strainer. In three patients, single-cell suspensions were cultured on collagen-coated plates, and adherent cells were re-established in secondary culture as either spheres or monolayers. In one patient, tumor cells obtained from a relapse biopsy were also directly placed in sphere culture.

Sphere culture and analysis. Tumor cells from monolayer cultures were seeded at 2,000 cells/well ( 1 cell $/ \mu 1$, cell lines) and/or 10,000 cells/well (5 cells/ $\mu 1$, primary cell cultures) in ultra-low attachment 6-well plates (Costar, Corning, NY, USA). The serum-free sphere culture medium was adjusted from a published report (12) and consisted of DMEM/F12 (1:1) supplemented with 4\% B27 (reagents from Invitrogen), $20 \mathrm{ng} / \mathrm{ml}$ recombinant human epidermal growth factor (rhEGF; Strathmann Biotech, Hamburg, Germany), $20 \mathrm{ng} / \mathrm{ml}$ leukaemia inhibitory factor (LIF; $20 \mathrm{ng} / \mathrm{ml})$, and $10 \mathrm{IE} / \mathrm{ml}(5 \mu \mathrm{g} / \mathrm{ml})$ heparin (Roche, Mannheim, Germany). rhEGF was added once on day 4 or 5. Maximum perpendicular sphere diameters were quantified with an inverted microscope using an eyepiece reticle with scales (Carl Zeiss, Goettingen, Germany). Spheres of various diameters were resuspended, and total numbers of viable cells were quantified by microscopy and trypan blue exclusion. Simple linear regression analysis was performed to establish the relationship between sphere diameters and cell counts.

Flow cytometry. Ewing sarcoma cells were stained with fluorescein-conjugated mAbs directed against CD117 (clone 104D2), CD99 (clone TÜ12), (BD Pharmingen, Heidelberg, Germany), CD133 (clone AC133; Miltenyi Biotec, Bergisch Gladbach, Germany), and CD57 (clone NC1; Beckman Coulter, Krefeld, Germany). For each sample, 20,000 cells were analyzed with FACSCalibur and BD CellQuest software or with FACSCanto and FACSDiva software. Relative fluorescence intensities
(RFI) were calculated by dividing median fluorescence intensities of mAb-stained cells by those obtained with isotype antibodies or in the absence of antibody.

Side population (SP) cell assay. Ewing sarcoma cells were resuspended from either monolayer or sphere cultures in culture medium. Viable cells $\left(0.2-0.3 \times 10^{6}\right)$ were incubated with the fluorescent dye Hoechst 33342 at a concentration of $2 \mu \mathrm{g} / \mathrm{ml}$ at $37^{\circ} \mathrm{C}$ and $5 \% \mathrm{CO}_{2}$ for $90 \mathrm{~min}$. Verapamil $(50 \mu \mathrm{M})$ (Sigma-Aldrich, Munich, Germany) was added to parallel samples to prevent Hoechst exclusion from SP. After staining, the cells were pelleted at $4^{\circ} \mathrm{C}$, and the pellets were resuspended in ice-cold Hank's balanced salt solution (HBSS) with $2 \%$ FCS, $10 \mathrm{mM}$ HEPES and $2 \mu \mathrm{g} / \mathrm{ml}$ propidium iodide (PI). For each sample, 15,000-25,000 cells were analyzed using a BD FACSAria II and FACSDiva Software. Hoechst 33342 was excited at $375 \mathrm{~nm}$, and fluorescence emission was detected using 450DF20 (blue) and LP670 (far-red) filters. Non-viable cells were excluded on the basis of PI uptake.

Mouse model. Mouse experiments were approved by the animal care committee of the local government (Bezirksregierung Muenster, Az. 87-51.04.2010.A117). Ewing sarcoma cells growing as spheres in serum-free medium and cells growing as monolayers under standard growth conditions were resuspended using cell dissociation solution $(0.04 \mathrm{M}$ Tris- $\mathrm{HCl}$, 1 mM EDTA, $0.15 \mathrm{M} \mathrm{NaCl}, \mathrm{pH}$ 7.4). Equal numbers of cells from each cell preparation were injected subcutaneously into the right and left flank, respectively, of eight to 12-week old NOD scid $\gamma$ (NSG) mice (Charles River Laboratories, Sulzfeld, Germany), and tumor growth was monitored twice a week by caliper quantification of diameters.

Statistical analysis. Data were analyzed descriptively using box-and-whisker plots. The box corresponds to the 25th/75th percentile. Whiskers were drawn from the ends of the box to the 5th and 95th percentile of data values. The Mann-Whitney $\mathrm{U}$ test was used to compare mean values in Fig. 2. $\mathrm{P}<0.05$ was considered to indicate a statistically significant difference. Statistical analyses were performed using PASW statistics 18 for Windows (SPSS Inc., Chicago, IL, USA).

\section{Results}

Ewing sarcoma cells grow as spheres when cultured under anchorage-independent serum-free conditions. Ewing sarcoma cells from five established cell lines were plated at 1 cell $/ \mu 1$ in serum-free medium with minimal supplements. Macroscopically visible spheres, corresponding to $>120 \mu \mathrm{m}$ diameters, reliably appeared within 8-9 days in four of the cell lines (VH-64, TC-32, TC-71 and A4573) (Fig. 1A), while WE-68 cells failed to form spheres in four individual experiments. Median sphere diameters varied between individual cell lines. Early passages of VH-64 cells (VH-64-EP) seeded at $1 \mathrm{cell} / \mu 1$ medium grew as spheres with comparable median diameters to the established cell line (VH-64). To establish the capacity of early tumor cell cultures to form spheres under serum-free conditions, we initiated parallel monolayer and anchorage-independent sphere cultures of tumor cells from biopsy material. Tumor biopsies were obtained from 
A

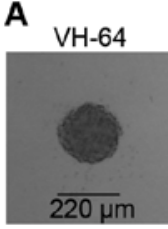

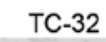

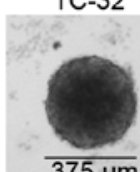

$375 \mu \mathrm{m}$
TC-71

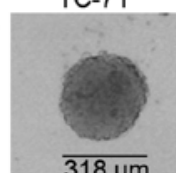

$\overline{318 \mu \mathrm{m}}$
A4573

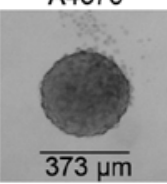

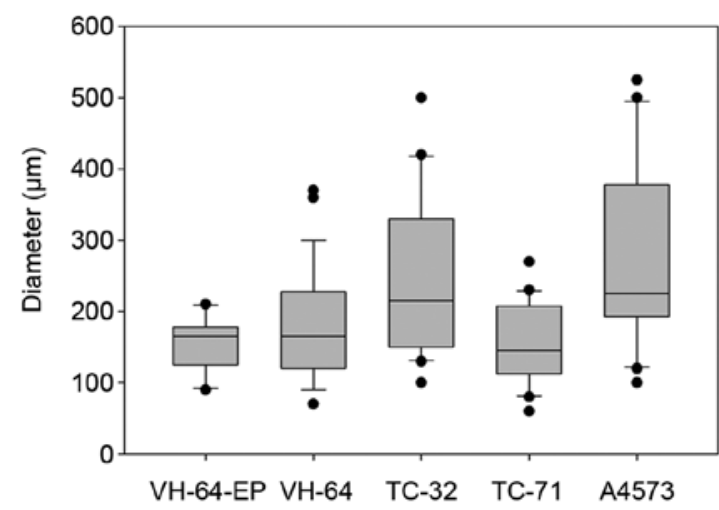

B
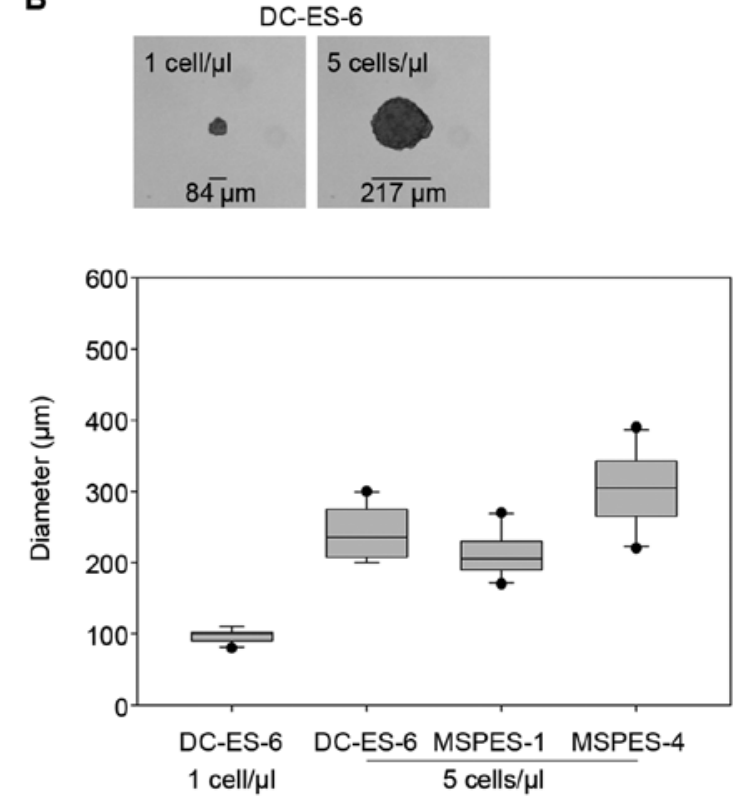

Figure 1. Ewing sarcoma cells from (A) cell lines and (B) early cell cultures form spheres in serum-free medium. (A) Ewing sarcoma cells were resuspended from monolayers and seeded at 1 cell $/ \mu 1$ medium in low attachment plates under serum-free conditions for $8-9$ days. Medians and ranges derive from 10 to 30 individual spheres, and boxes represent the 25 th and 75 th percentiles. (B) Sphere diameters after seeding tumor cells from early cell cultures at 1 cell/ $\mu 1$ did not exceed $120 \mu \mathrm{m}$. DC-ES-6 spheres are shown as an example. Higher seeding densities (5 cells/ $\mu 1)$ generated macroscopically visible spheres from primary tumor cell cultures. Medians and ranges were determined from 10 individual spheres each.

Table I. Clinical and molecular characteristics of Ewing sarcoma patients whose biopsies were used to generate primary cell cultures.

\begin{tabular}{|c|c|c|c|c|c|}
\hline Patient & $\begin{array}{c}\text { Age at first } \\
\text { diagnosis (years) }\end{array}$ & $\begin{array}{l}\text { Primary tumor } \\
\text { localization }\end{array}$ & Current biopsy & Translocation & Clinical outcome \\
\hline MSPES-1 & 15 & Localized, femur & $\begin{array}{l}\text { Disseminated relapse } \\
\text { (soft tissue metastasis) }\end{array}$ & $\mathrm{t}(11 ; 22)$ & $\begin{array}{l}\text { DOD } 36 \text { mo } \\
\text { after diagnosis }\end{array}$ \\
\hline MSPES-4 & 20 & $\begin{array}{l}\text { Pelvis + pulmonary } \\
\text { metastases }\end{array}$ & $\begin{array}{l}\text { Disseminated relapse } \\
\text { (liver metastasis) }\end{array}$ & $\mathrm{t}(11 ; 22)$ & $\begin{array}{l}\text { PD } 22 \text { mo } \\
\text { after diagnosis }\end{array}$ \\
\hline DC-ES-6 & 9 & $\begin{array}{l}\text { Pelvis }+ \text { bone } \\
\text { metastases }\end{array}$ & $\begin{array}{l}\text { Progressive disease } \\
\text { (vertebral column) }\end{array}$ & $\mathrm{t}(11 ; 22)$ & $\begin{array}{l}\text { DOD } 9 \text { mo } \\
\text { after diagnosis }\end{array}$ \\
\hline MSPES-5 & 11 & $\begin{array}{l}\text { Multifocal bone }+ \\
\text { pulmonary metastases }\end{array}$ & Pulmonary relapse & $\mathrm{t}(21 ; 22)$ & $\begin{array}{l}\text { PD } 16 \text { mo after } \\
\text { diagnosis }\end{array}$ \\
\hline
\end{tabular}

DOD, died of disease.

patients with disseminated Ewing sarcomas at either primary diagnosis or at relapse (Table I). The identity of the cultures was confirmed by the presence of the $t(11 ; 22)$ translocation by RT-PCR analysis and by homogeneous expression of CD99 by flow cytometry. Re-establishment of tumor cells from one initial monolayer passage generated small, microscopically visible spheres (Fig. 1B). Seeding of tumor cells at higher densities of 5 cells $/ \mu 1$ resulted in larger spheres with comparable sizes to those derived from established cell lines (Fig. 1B).

Ewing sarcoma spheres and monolayers share a similar phenotype. To investigate whether monolayer vs. serum-free sphere culture conditions affect the cellular phenotype of Ewing sarcoma cells, we compared surface expression of various cellular and differentiation markers, including markers previously associated with functional stem cell characteristics (Fig. 2A and B). The MIC2 gene product CD99, which is used as a diagnostic marker of Ewing sarcoma, was strongly expressed by all cell lines, and expression was unaffected by the type of cell culture. Moreover, the tyrosine kinase CD117 (c-KIT), which was found to have a role in survival and metastasis of Ewing sarcoma (16), did not vary between monolayers and spheres. CD133 has been proposed as a marker of tumor-initiating cells (17). In our system, CD133 expression did not vary between spheres and monolayers. CD57 (HNK-1) is a marker for neural crest stem cells and was previously associated with sphere growth and tumorigenicity in Ewing sarcoma (14). Cell surface density of CD57 was highly variable among spheres 
A
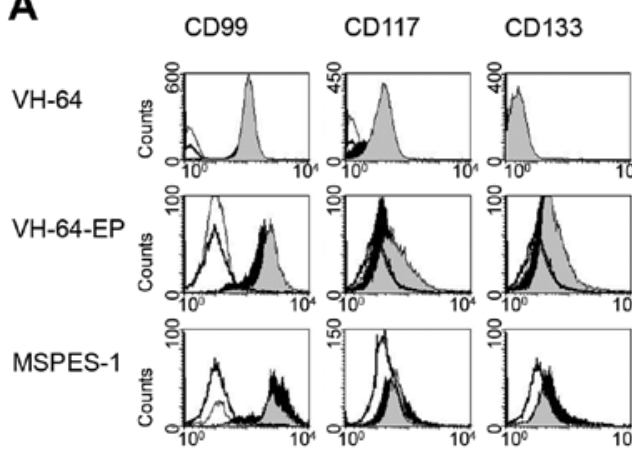

DC-ES-6
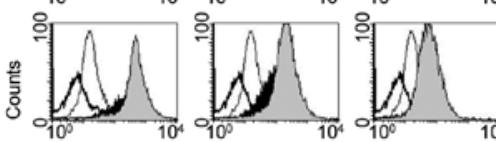

MSPES-4
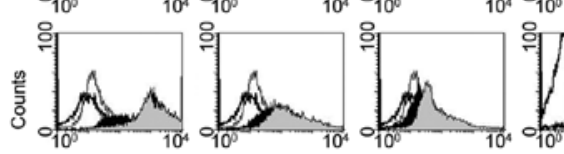

Spheres

$\square$ Spheres, unstained control

\section{Monolayers}

Monolayers, unstained control
B
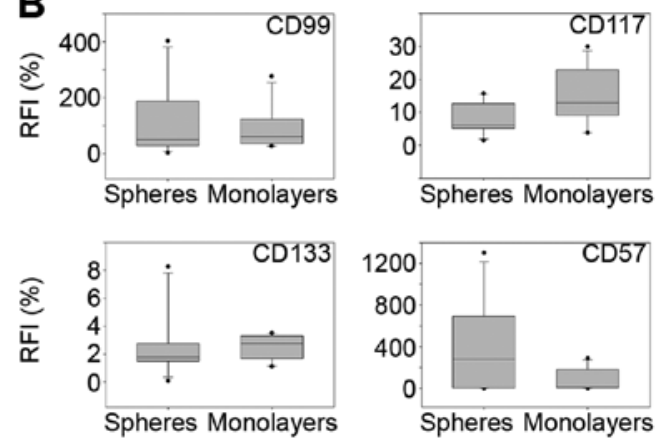

C

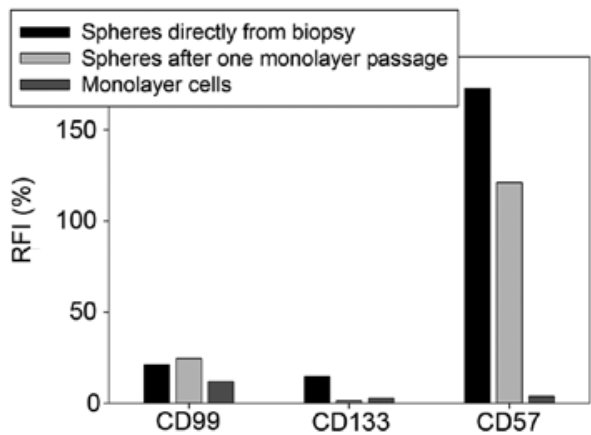

Figure 2. Phenotypes of Ewing sarcoma cells grown as monolayers and spheres. (A) Ewing sarcoma cells were resuspended from monolayers and spheres, respectively, and stained with monoclonal antibodies against the indicated surface markers. A representative experiment of two is shown. (B) Medians and ranges were calculated from duplicate values for the median relative fluorescence intensities of staining of the following cell lines and early-passage cultures: VH-64, TC-71, VH-64-EP, DC-ES-6, MSPES-1 and MSPES-4. Boxes represent the 25th and 75th percentiles. Differences were not statistically significant. (C) MSPES-5 Ewing sarcoma cells were obtained from a tumor biopsy, then either seeded directly into serum-free sphere culture, or after one monolayer passage. Monolayer cultures were established in parallel. Cells resuspended from the three types of cultures were stained and analyzed as above.
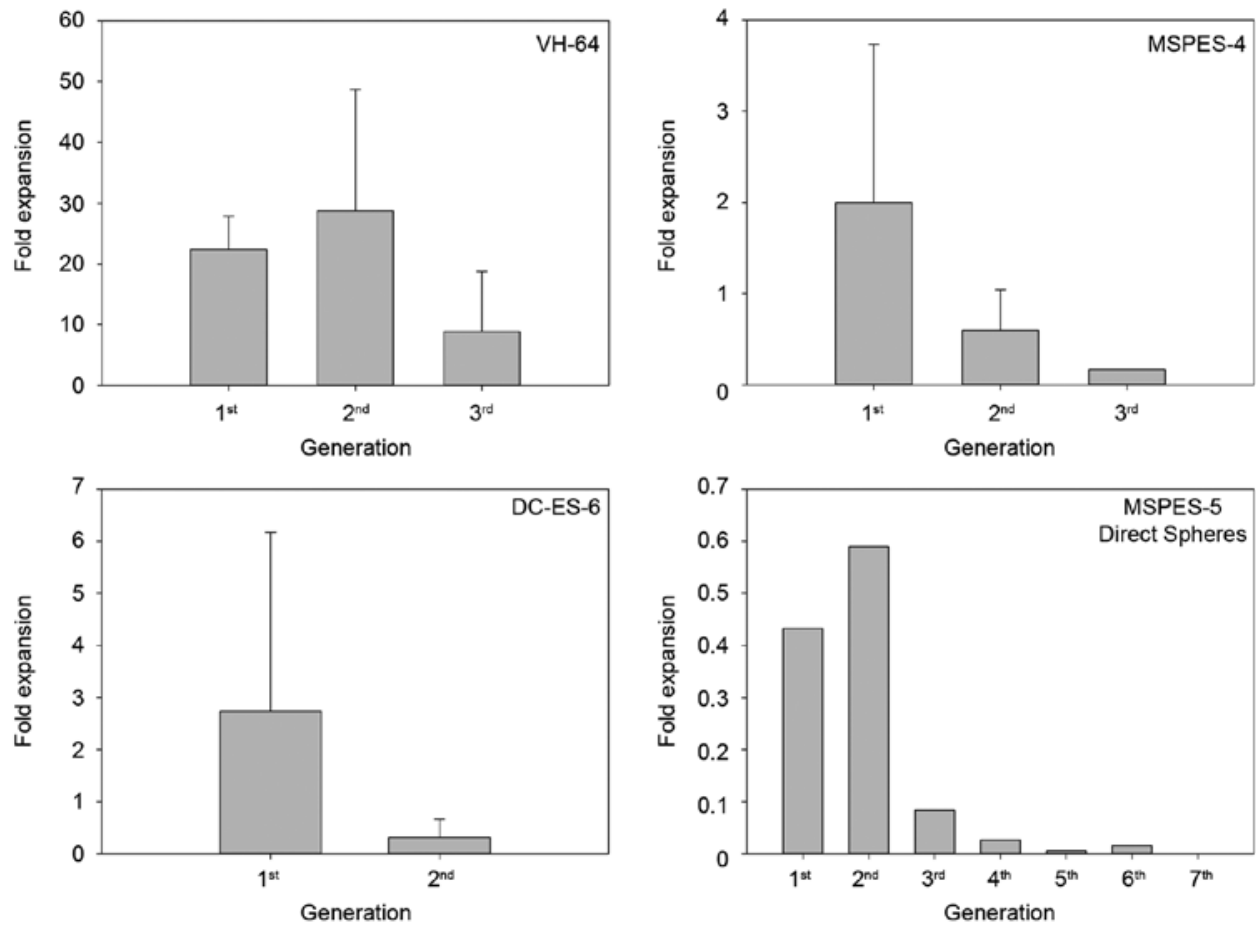

Figure 3. Ewing sarcoma sphere-derived cells fail to consistently form secondary spheres in serum-free medium. Tumor cells from spheres were disintegrated, followed by secondary replating under the same serum-free growth conditions at 1 cell $/ \mu 1$ (VH-64) and 5 cells/ $\mu 1$ (MSPES-4, DC-ES-6, MSPES-5), respectively.

but median expression did not significantly differ from monolayer cultures. To exclude that primary passaging as monolayer cultures on collagen-coated plates had affected the characteristics of Ewing sarcoma spheres, we initiated spheres directly from fresh tumor dissociates of a relapse biopsy in an additional patient (MSPES-5) and compared the phenotype 

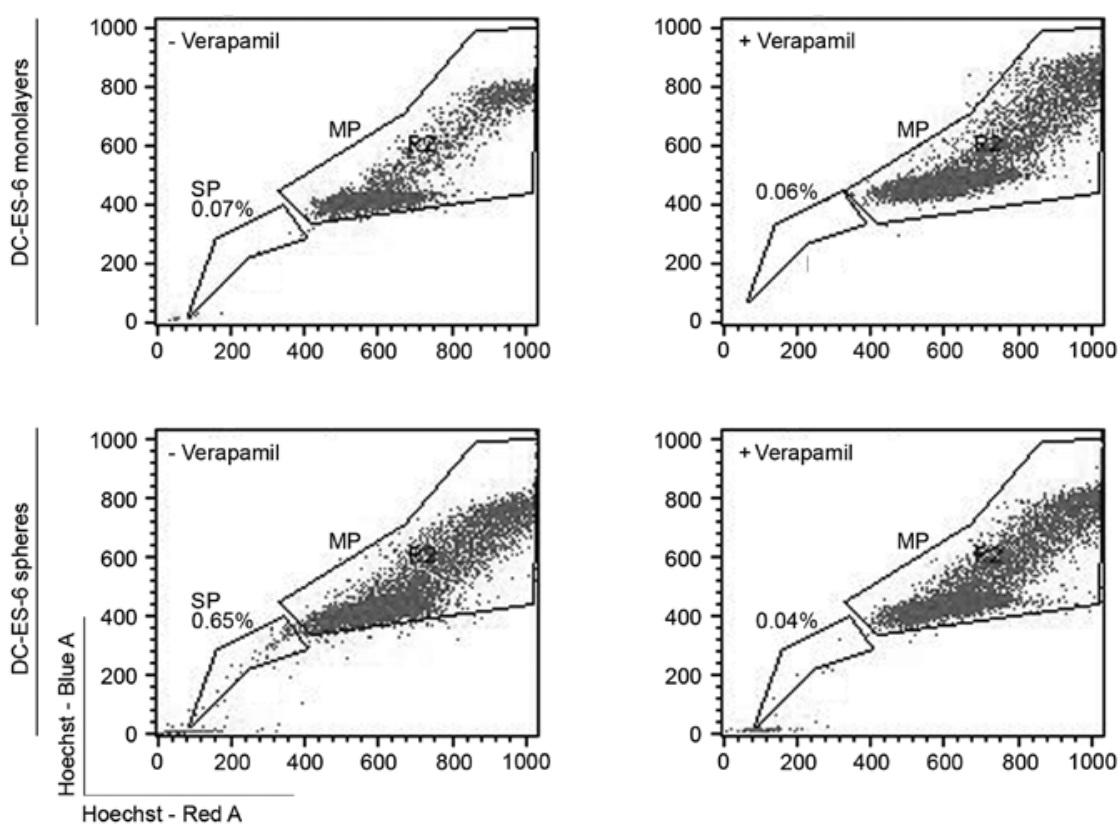

Figure 4. Ewing sarcoma spheres do not consistently contain SPs. Spheres and monolayers of the VH-64 cell line and of DC-ES-6 and MSPES-4 low-passage cultures were cultured for 8 days, mechanically dissociated and stained with Hoechst 33342 dye to determine SP. The gate was limited to propidium iodide negative cells. Addition of verapamil prevents Hoechst exclusion from SP. SP, side population.

to MSPES-5 spheres generated via one monolayer passage. While CD57 expression in this cell line was substantially higher on spheres compared to monolayers, no difference was observed between the two types of spheres (Fig. 2C). Thus, a single monolayer passage in serum-containing medium did not affect the phenotype of subsequent sphere cultures compared to spheres directly initiated from biopsy material. Taken together, phenotyping did not reveal any consistent and significant differences between spheres and monolayers.

Sphere cultures from Ewing sarcoma cells have limited ability to self-renew in vitro. In glioblastoma and other solid tumors, sphere growth in serum-free medium was associated with enhanced self-renewal $(18,19)$. Upon disintegration and secondary replating of VH-64 spheres, single cells continued to form spheres in serum-free culture (Fig. 3). However, in contrast to the established cell line, primary tumor cell cultures could not be maintained as spheres for more than 2-3 passages, while parallel monolayer cultures were successfully established and passaged multiple times. Cells obtained directly from fresh tumor dissociates (MSPES-5) efficiently formed initial spheres, but subsequent replating of spherederived cells resulted in a progressive loss of viable cells, and sphere cultures could not be maintained. Thus, Ewing sarcoma cells are unable to reliably and continuously form secondary spheres under growth-constraining conditions, arguing against the presence of self-renewing primitive cells in these cultures.

Sphere cultures of Ewing sarcoma cells contain variable proportions of SPs. To further address the functional stem cell characteristics of Ewing sarcoma spheres, we compared the capacity of sphere- vs. monolayer-cultured cells to enrich for SP cells. The SP assay relies on the high drug efflux activity of a subset of cells with supposed tumor-propagating activity and multi-drug chemoresistance, which is identified by exclu-
Table II. Proportions of SP among VH-64, DC-ES-6 and MSPES-4 cells cultured for 8 days as spheres or monolayers, determined by Hoechst 33342 dye exclusion and gating on propidium iodide negative cells; addition of verapamil prevents Hoechst exclusion from SP.

\begin{tabular}{|c|c|c|c|c|}
\hline \multirow[b]{2}{*}{ Cell line } & \multicolumn{2}{|c|}{ Monolayers } & \multicolumn{2}{|c|}{ Spheres } \\
\hline & $\begin{array}{l}\text { - Verapamil } \\
(\%)\end{array}$ & $\begin{array}{c}+ \text { Verapamil } \\
(\%)\end{array}$ & $\begin{array}{c}\text { - Verapamil } \\
(\%)\end{array}$ & $\begin{array}{c}+ \text { Verapamil } \\
(\%)\end{array}$ \\
\hline \multirow[t]{4}{*}{ VH-64 } & 0.23 & 0.04 & 0.16 & 0.03 \\
\hline & 0.39 & 0.70 & 0.17 & 0.00 \\
\hline & 0.19 & 0.01 & 0.52 & 0.01 \\
\hline & 0.06 & 0.02 & 1.46 & 0.01 \\
\hline \multirow[t]{2}{*}{ DC-ES-6 } & 0.01 & 0.01 & 0.31 & 0.15 \\
\hline & 0.07 & 0.06 & 0.65 & 0.04 \\
\hline MSPES-4 & 0.03 & 0.08 & 0.27 & 0.30 \\
\hline
\end{tabular}

SP, side population.

sion of the fluorescent dye Hoechst 33342 (20). To investigate whether sphere culture enriches for cells with these properties, we quantified the SP in resuspended monolayer and sphere cultures of VH-64 cells and in two of the primary Ewing sarcoma cell cultures (Fig. 4, Table II). Results largely varied between independent experiments even under identical culture conditions. In VH-64 cells, SPs were detected in 4/4 sphere cultures and 2/4 monolayer cultures. Whereas all MSPES-4 cultures lacked SPs, DC-ES-6 sphere cultures but not monolayers reproducibly had SPs. We conclude that SPs are not a reliable characteristic of Ewing sarcoma cell cultures irrespective of in vitro culture conditions. 
Table III. Ewing sarcoma cells derived from sphere culture do not exhibit higher in vivo tumorigenicity than monolayer cells. ${ }^{\text {a }}$

Incidence of tumor generation

\begin{tabular}{|c|c|c|c|c|c|}
\hline \multicolumn{2}{|c|}{ VH-64 } & \multicolumn{2}{|c|}{ MSPES-4 } & \multicolumn{2}{|c|}{ DC-ES-6 } \\
\hline Monolayer & Spheres & Monolayer & Spheres & Monolayer & Spheres \\
\hline $0 / 2$ & $0 / 2$ & $1 / 4$ & $0 / 4$ & $0 / 4$ & $0 / 4$ \\
\hline $1 / 2$ & $1 / 2$ & $1 / 4$ & $3 / 4$ & $1 / 4$ & $1 / 4$ \\
\hline
\end{tabular}

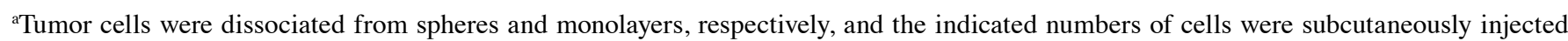
into the left and right flanks of NSG mice.

Sphere culture of Ewing sarcoma cells does not enhance their in vivo tumorigenicity. To directly compare the tumorigenicity of Ewing sarcoma cells, we transplanted increasing numbers of VH-64, MSPES-4 and DC-ES-6 cells derived from sphere vs. standard monolayer cultures subcutaneously into the left vs. right flanks of immunodeficient NSG mice. Transplantation of $5 \times 10^{4}$ MSPES-4 tumor cells derived from monolayer culture formed a solid tumor in one of four mice after 10 weeks, whereas analogous numbers of sphere-cultured MSPES-4 cells failed to induce tumors (Table III). Injection of $5 \times 10^{4}$ tumor cells from VH-64 and DC-ES-6 did not result in subcutaneous tumor growth regardless of the culture conditions. Higher numbers of $2.5 \times 10^{5}$ tumor cells established solid tumors from all three cell lines/cultures in a proportion of transplanted animals (Table III). No consistent differences in the capacity to initiate tumors were observed between monolayers and sphere-cultured cells throughout the three cell lines. These data strongly argue against a higher tumorigenicity of sphere-cultured cells.

\section{Discussion}

Sphere growth of glioblastoma and other solid cancer cell lines under growth-constraining conditions was found to represent and select for cells with self-renewing and clonogenic potential that were tumorigenic in vivo (12,19,21-29). In the present study, we showed that anchorage-independent growth of Ewing sarcoma cells in serum-free medium is not associated with stem-cell like phenotype and behavior. Throughout various cell lines and biopsy-derived cell cultures, sphere-cultured Ewing sarcoma cells had a limited capacity to self-renew by continued sphere formation. Moreover, sphere-derived cells were not superior to monolayer-cultured cells to initiate tumors in immunodeficient mice. These results appear to be inconsistent with previous reports of an enhanced tumorigenicity of cells from solid tumor spheres, including one study in Ewing sarcoma (14). A potential reason for discrepant functional results in individual investigations is that spheres from extracranial tumors were often generated from established cell lines $(14,25,29)$. Although cellular hierarchies of tumorigenicity can be preserved in some cancer cell lines (30), freshly isolated primary tumor samples and early cultures of tumor cells more closely reflect the biology of the disease. Here, we were able to establish parallel sphere and monolayer cultures of CD99 ${ }^{\text {high }}$ Ewing sarcoma cells from four relapse biopsies.
Among individual Ewing sarcoma cell lines and cultures, we observed substantial heterogeneity of both phenotype and function. However, of four biopsies, all obtained from patients with aggressive, relapsed disease, none was able to reinitiate spheres in vitro for more than 2-3 passages. Thus, failure to self-renew in vitro was a common characteristic of various Ewing sarcomas.

Further arguments against the enrichment of Ewing sarcoma spheres for cells with cancer stem cell properties were obtained by phenotyping and side population (SP) analysis. Expression of CD133 has been associated with higher tumorigenicity of individual subpopulations in various solid tumors $(19,31,32)$, although the role of this marker in Ewing sarcoma is controversial. Following one report that CD133 expression indeed marks a subpopulation of Ewing sarcoma cells with tumor-initiating capacity (17), others found that this association was restricted to a limited proportion of Ewing sarcomas (33). An alternative surface marker proposed to reflect enhanced tumorigenicity in Ewing sarcoma is the neural crest stem cell marker CD57 (14). In the present study, expression of both CD133 and CD57 was variable among individual cell lines and cultures. While individual cell cultures had substantially higher surface CD57 expression than the respective monolayers, no consistent association with the two culture conditions was identified. The heterogeneity of our findings argues against a significant role of CD133 and CD57 as markers of cells with tumor-initiating capacity in Ewing sarcomas. The potential of SPs identified by exclusion of the fluorescent dye Hoechst 33342 to reflect the cancer stem cell pool in solid malignancies remains a matter of debate. Although SPs were shown to define a cell population with cancer stem cell characteristics in some tumors $(34,35)$, failure of SP to represent the cancer stem cell compartment was reported in glioblastoma (36). Among the Ewing sarcoma cell lines and cultures investigated here, the presence of SPs was inconsistent, even between individual experiments using the same cell line. Thus, Hoechst dye 33342 exclusion does not appear to be a reliable marker of subpopulations with distinct characteristics in Ewing sarcoma. Ultimately, we obtained in vivo evidence in a highly immunodeficient mouse model that the tumorigenicity of sphere-derived Ewing sarcoma cells is low and not superior to tumor cells cultured as monolayers.

We conclude that tumor spheres propagated in the absence of serum can not be generally assumed to be enriched for cells with tumor-initiating capacity in Ewing sarcoma. Tumorigenic subsets may be heterogeneous, dynamic and 
sensitive to undergo phenotypic and functional alterations during both in vitro and in vivo growth. Reliable phenotypes and functional characteristics that enrich for subpopulations with stem-cell like properties have not yet been identified in this disease. Such markers could be useful for the development of novel therapeutics, since tumor-initiating subpopulations of solid cancers are considered the prime targets of therapy (37).

From the translational point of view, the sphere model, despite its inadequacy to reflect tumor-initiating properties, may be a useful additional tool for preclinical in vitro testing of novel therapies. Three-dimensional in vitro culture models are now increasingly acknowledged for preclinical evaluation of immunotherapeutics and mechanisms of immune evasion (38-41). In Ewing sarcoma, susceptibility of tumor cells to lysis by NK cells was indeed found to critically depend on in vitro culture conditions, with multicellular clusters being substantially more resistant than monolayers or single cell suspensions (4). This discrepancy provides a potential explanation why the potent antitumor activity of NK cells in preclinical experiments $(42,43)$ fails to translate into clinical responses to adoptive transfer of these cells $(43,44)$. Thus, even in the absence of the capacity to enrich for tumor-initiating cells, sphere cultures of tumor cells could add information to the preclinical evaluation of novel drugs and immune targeted therapies.

\section{Acknowledgements}

Statistical support was provided by René Schmidt, Institute of Biostatistics and Clinical Research. The present study was supported by an institutional grant by IMF Muenster (AL 121005 , to C.R. and B.A.), by funding provided by the local charity 'Freundeskreis KMT' (to K.L), and by a grant from the Dr Mildred-Scheel-Stiftung der Deutschen Krebshilfe (109566, to C.R.).

\section{References}

1. Paulussen M, Craft AW, Lewis I, et al: Results of the EICESS-92 study: two randomized trials of Ewing's sarcoma treatment cyclophosphamide compared with ifosfamide in standard-risk patients and assessment of benefit of etoposide added to standard treatment in high-risk patients. J Clin Oncol 26: 4385-4393, 2008.

2. Paulussen M, Ahrens S, Burdach S, et al: Primary metastatic (stage IV) Ewing tumor: survival analysis of 171 patients from the EICESS studies. European Intergroup Cooperative Ewing Sarcoma Studies. Ann Oncol 9: 275-281, 1998.

3. Stahl M, Ranft A, Paulussen M, et al: Risk of recurrence and survival after relapse in patients with Ewing sarcoma. Pediatr Blood Cancer 57: 549-553, 2011.

4. Cho D, Shook DR, Shimasaki N, Chang YH, Fujisaki H and Campana D: Cytotoxicity of activated natural killer cells against pediatric solid tumors. Clin Cancer Res 16: 3901-3909, 2010.

5. Mackall CL, Rhee EH, Read EJ, et al: A pilot study of consolidative immunotherapy in patients with high-risk pediatric sarcomas. Clin Cancer Res 14: 4850-4858, 2008.

6. Thiel U, Pirson S, Müller-Spahn C, et al: Specific recognition and inhibition of Ewing tumour growth by antigen-specific allorestricted cytotoxic T cells. Br J Cancer 104: 948-956, 2011.

7. Erkizan HV, Kong Y, Merchant M, et al: A small molecule blocking oncogenic protein EWS-FLI1 interaction with RNA helicase A inhibits growth of Ewing's sarcoma. Nat Med 15 750-756, 2009.

8. Braun S, Pantel K, Müller P, et al: Cytokeratin-positive cells in the bone marrow and survival of patients with stage I, II, or III breast cancer. N Engl J Med 342: 525-533, 2000.
9. Woelfle U, Breit E, Zafrakas K, et al: Bi-specific immunomagnetic enrichment of micrometastatic tumour cell clusters from bone marrow of cancer patients. J Immunol Methods 300: 136-145, 2005.

10. Freedman VH and Shin SI: Cellular tumorigenicity in nude mice: correlation with cell growth in semi-solid medium. Cell 3: 355-359, 1974.

11. Shin SI, Freedman VH, Risser R and Pollack R: Tumorigenicity of virus-transformed cells in nude mice is correlated specifically with anchorage independent growth in vitro. Proc Natl Acad Sci USA 72: 4435-4439, 1975.

12. Lee J, Kotliarova S, Kotliarov Y, et al: Tumor stem cells derived from glioblastomas cultured in bFGF and EGF more closely mirror the phenotype and genotype of primary tumors than do serum-cultured cell lines. Cancer Cell 9: 391-403, 2006.

13. Lawlor ER, Scheel C, Irving J and Sorensen PH: Anchorageindependent multi-cellular spheroids as an in vitro model of growth signaling in Ewing tumors. Oncogene 21: 307-318, 2002.

14. Wahl J, Bogatyreva L, Boukamp P, et al: Ewing's sarcoma cells with CD57-associated increase of tumorigenicity and with neural crest-like differentiation capacity. Int J Cancer 127: 1295-1307, 2010.

15. Ottaviano L, Schaefer KL, Gajewski M, et al: Molecular characterization of commonly used cell lines for bone tumor research: a trans-European EuroBoNet effort. Genes Chromosomes Cancer 49: 40-51, 2010.

16. Landuzzi L, De Giovanni C, Nicoletti G, et al: The metastatic ability of Ewing's sarcoma cells is modulated by stem cell factor and by its receptor $c$-kit. Am J Pathol 157: 2123-2131, 2000.

17. Suvà ML, Riggi $\mathrm{N}$, Stehle JC, et al: Identification of cancer stem cells in Ewing's sarcoma. Cancer Res 69: 1776-1781, 2009.

18. Al Hajj M, Wicha MS, Benito-Hernandez A, Morrison SJ and Clarke MF: Prospective identification of tumorigenic breast cancer cells. Proc Natl Acad Sci USA 100: 3983-3988, 2003.

19. Singh SK, Hawkins C, Clarke ID, et al: Identification of human brain tumour initiating cells. Nature 432: 396-401, 2004.

20. Goodell MA, Rosenzweig M, Kim H, et al: Dye efflux studies suggest that hematopoietic stem cells expressing low or undetectable levels of CD34 antigen exist in multiple species. Nat Med 3: 1337-1345, 1997.

21. Coulon A, Flahaut M, Mühlethaler-Mottet A, et al: Functional sphere profiling reveals the complexity of neuroblastoma tumorinitiating cell model. Neoplasia 13: 991-1004, 2011.

22. Hansford L, Smith K, Datti A, et al: Tumor initiating cells from neuroblastoma, a neural crest-derived tumor. Int J Dev Neurosci 24: 489, 2006

23. Mahller YY, Williams JP, Baird WH, et al: Neuroblastoma cell lines contain pluripotent tumor initiating cells that are susceptible to a targeted oncolytic virus. PLoS One 4: e4235, 2009.

24. Rainusso N, Brawley VS, Ghazi A, et al: Immunotherapy targeting HER2 with genetically modified T cells eliminates tumor-initiating cells in osteosarcoma. Cancer Gene Ther 19: 212-217, 2012.

25. Walter D, Satheesha S, Albrecht P, et al: CD133 positive embryonal rhabdomyosarcoma stem-like cell population is enriched in rhabdospheres. PLoS One 6: e19506, 2011.

26. Zhang S, Balch C, Chan MW, et al: Identification and characterization of ovarian cancer-initiating cells from primary human tumors. Cancer Res 68: 4311-4320, 2008.

27. Brown CE, Starr R, Martinez C, et al: Recognition and killing of brain tumor stem-like initiating cells by $\mathrm{CD} 8^{+}$cytolytic $\mathrm{T}$ cells. Cancer Res 69: 8886-8893, 2009.

28. Gibbs CP, Kukekov VG, Reith JD, et al: Stem-like cells in bone sarcomas: implications for tumorigenesis. Neoplasia 7: 967-976, 2005.

29. Zhong Y, Guan K, Guo S, et al: Spheres derived from the human SK-RC-42 renal cell carcinoma cell line are enriched in cancer stem cells. Cancer Lett 299: 150-160, 2010.

30. Charafe-Jauffret E, Ginestier C, Iovino F, et al: Breast cancer cell lines contain functional cancer stem cells with metastatic capacity and a distinct molecular signature. Cancer Res 69: 1302-1313, 2009.

31. O'Brien CA, Pollett A, Gallinger S and Dick JE: A human colon cancer cell capable of initiating tumour growth in immunodeficient mice. Nature 445: 106-110, 2007.

32. Yin S, Li J, Hu C, et al: CD133 positive hepatocellular carcinoma cells possess high capacity for tumorigenicity. Int J Cancer 120: 1444-1450, 2007

33. Jiang X, Gwye Y, Russell D, et al: CD133 expression in chemoresistant Ewing sarcoma cells. BMC Cancer 10: 116, 2010. 
34. Hirschmann-Jax C, Foster AE, Wulf GG, et al: A distinct 'side population' of cells with high drug efflux capacity in human tumor cells. Proc Natl Acad Sci USA 101: 14228-14233, 2004

35. Murase M, Kano M, Tsukahara T, et al: Side population cells have the characteristics of cancer stem-like cells/cancer-initiating cells in bone sarcomas. Br J Cancer 101: 1425-1432, 2009.

36. Broadley KW, Hunn MK, Farrand KJ, et al: Side population is not necessary or sufficient for a cancer stem cell phenotype in glioblastoma multiforme. Stem Cells 29: 452-461, 2011.

37. Barrett LE, Granot Z, Coker C, et al: Self-renewal does not predict tumor growth potential in mouse models of high-grade glioma. Cancer Cell 21: 11-24, 2012.

38. Feder-Mengus C, Ghosh S, Weber WP, et al: Multiple mechanisms underlie defective recognition of melanoma cells cultured in three-dimensional architectures by antigen-specific cytotoxic T lymphocytes. Br J Cancer 96: 1072-1082, 2007.

39. Fischer K, Hoffmann P, Voelkl S, et al: Inhibitory effect of tumor cell-derived lactic acid on human T cells. Blood 109: 3812-3819, 2007.
40. Hirschhaeuser F, Leidig T, Rodday B, Lindemann C and Mueller-Klieser W: Test system for trifunctional antibodies in 3D MCTS culture. J Biomol Screen 14: 980-990, 2009.

41. Jääskeläinen J, Kalliomäki P, Paetau A and Timonen T: Effect of LAK cells against three-dimensional tumor tissue. In vitro study using multi-cellular human glioma spheroids as targets. J Immunol 142: 1036-1045, 1989.

42. Lakshmikanth T, Burke S, Ali TH, et al: NCRs and DNAM-1 mediate NK cell recognition and lysis of human and mouse melanoma cell lines in vitro and in vivo. J Clin Invest 119: 1251-1263, 2009.

43. Parkhurst MR, Riley JP, Dudley ME and Rosenberg SA: Adoptive transfer of autologous natural killer cells leads to high levels of circulating natural killer cells but does not mediate tumor regression. Clin Cancer Res 17: 6287-6297, 2011.

44. Geller MA, Cooley S, Judson PL, et al: A phase II study of allogeneic natural killer cell therapy to treat patients with recurrent ovarian and breast cancer. Cytotherapy 13: 98-107, 2011. 